\section{Regards sur l'économie allemande}

Bulletin économique du CIRAC

$72 \mid 2005$

Varia

\title{
Secteur financier
}

SCHUSTER Leo, WIDMER Alex W. (ed.), Wege aus der Banken- und Börsenkrise / FRÖHLICH Nils, HUFFSCHMID Jörg, Der Finanzdienstleistungssektor in Deutschland. Entwicklung, Politik, Strategien / SCHÄFER Bernhard (ed.), Handbuch Regionalbanken

\section{(2)enEdition}

\section{Journals}

Édition électronique

URL : http://journals.openedition.org/rea/310

DOI : $10.4000 /$ rea. 310

ISBN : 978-2-8218-0840-9

ISSN : 1965-0787

Éditeur

CIRAC

Édition imprimée

Date de publication : 1 juillet 2005

ISSN : 1156-8992

Référence électronique

"Secteur financier », Regards sur l'économie allemande [En ligne], 72 I juillet 2005, document 5, mis en ligne le 24 avril 2008, consulté le 22 septembre 2020. URL : http://journals.openedition.org/rea/310 ; DOI : https://doi.org/10.4000/rea.310

Ce document a été généré automatiquement le 22 septembre 2020.

(c) CIRAC 


\section{Secteur financier}

SCHUSTER Leo, WIDMER Alex W. (ed.), Wege aus der Banken- und Börsenkrise / FRÖHLICH Nils, HUFFSCHMID Jörg, Der

Finanzdienstleistungssektor in Deutschland. Entwicklung, Politik, Strategien / SCHÄFER Bernhard (ed.), Handbuch Regionalbanken 


\section{RÉFÉRENCE}

SCHUSTER Leo, WIDMER Alex W. (ed.), Wege aus der Banken- und Börsenkrise,

Springer Verlag, Berlin Heidelberg, 2004, 527 p.

FRÖHLICH Nils, HUFFSCHMID Jörg, Der Finanzdienstleistungssektor in Deutschland.

Entwicklung, Politik, Strategien, edition der Hans Böckler Stiftung 101, Düsseldorf,

$2004,170 \mathrm{p}$.

SCHÄFER Bernhard (ed.), Handbuch Regionalbanken, Gabler Verlag, Wiesbaden, 2004, $401 \mathrm{p}$.

Depuis l'éclatement de la bulle spéculative des valeurs technologiques, le système bancaire et financier allemand traverse une situation tendue et se restructure. Ses entreprises et institutions sont contraintes de réduire leurs coûts (suppression de quelque 50000 emplois pour les seules grandes banques, réduction du réseau de filiales) et de rechercher de nouvelles stratégies (vente de participations industrielles, coopérations et fusions, réorganisation interne, internationalisation, etc.). L'étude publiée (Fröhlich, Huffschmid) par la Fondation Hans-Böckler, le centre de recherche de la Confédération syndicale DGB, s'intéresse à l'activité économique et aux contours d'un secteur (banques, assurances, fonds d'investissement) doublement fragilisé par une conjoncture nationale défavorable et par l'évolution des marchés financiers nationaux et internationaux. Elle s'interroge également sur les conséquences probables de l'évolution du cadre de régulation: libéralisation, Bâle II, suppression en 2005 des garanties publiques octroyées aux Caisses d'Epargne et banques régionales. Dans un contexte de concurrence renforcée, ces dernières doivent en effet adapter à leur tour leurs stratégies (Schäfer) voire appliquer de nouveaux instruments et méthodes pour sortir de la crise (Schuster, Widmer). (mhp) 